\title{
Analysis of the Change in Thickness of the Thin Double Reduced Steel Sheets by Drawing of Cups
}

\author{
Janka Majerníková', Emil Spišák ${ }^{1 *}$, L’uboš Kaščák', Ján Slota \\ 1 Technical University of Košice, Mäsiarska 74, 04001 Košice, Slovakia \\ * Corresponding author's e-mail: emil.spisak@tuke.sk
}

\begin{abstract}
During the processing of the thin packaging sheets by drawing, thickness of the material changes and so does the thickness of tin layer, this has an influence on corrosion resistance. Change in material thickness of the cylindrical cups without a flange has been evaluated in this contribution. Cups were produced from the double reduced continuously annealed packaging sheets. After cupping test, the anisotropy of these sheets was evaluated too, this was expressed through the earring formation on the cups.
\end{abstract}

Keywords: packaging sheets, tin layer, cupping test

\section{INTRODUCTION}

Production of the thin steel sheets used for the production of packages has been rising in all of the steel companies around the world. In order to achieve better material application, thickness of the thin steel sheets (thin packaging sheets) has been reduced in the recent years. Change in the material thickness has required the change in the production of these materials. During the cold rolling, a larger material reduction is required and thus a larger material deformation occurs, which, after annealing, has an influence on the strength and plastic properties of these sheets. In order for these sheets to be consequently processed, mainly by drawing, the material is being annealed after it has been rolled. Annealing used to be done in the form of batch annealing, however, because of the higher productivity, this process has been mostly replaced by the continuous strip annealing. During the continuous annealing, which happens at high speed of a moving strip, the grain size of a produced sheet is influenced by the size of deformation, temperature of annealing and time of annealing. General opinion is that the continuously annealed materials are used for the production of less demanding cups.
Apart from the change in the material thickness of the packaging sheets, thickness of the tin layer has been considerably reduced in the recent years as well. This reduction has been a consequence of the scarce tin resources in the world. In the case of many types of sheets, thickness of the tin layer has decreased down to approximately $1 \mathrm{~g} / \mathrm{m}^{2}$. Tin layer plays a very important role in the protection of the packaging sheets. It protects main material with its entirety. Entirety of the tin layer can be violated by the deformation of main material (steel sheet). During the processing of the thin packaging sheets by drawing, various stressstrain states occur [1-3]. From the point of view of the tin layer entirety, the tensile stress is the most favourable one. It is assumed that the thickness of the protection tin layer should correspond with the change in the material thickness. That is why it is very important to analyse the change in the material thickness during the drawing.

That is the reason why this contribution focuses on the examination of the change in the material thickness during the drawing of cylindrical cups. Cupping test was performed on the selected experimental materials produced by continuous annealing. Earring and the change in the thickness of the main material of the cups were evaluated after the cupping test. 


\section{EXPERIMENTAL MATERIAL}

The four grades of the thin tin coated double reduced continuously annealed packaging sheets of the nominal thickness $0.17 \mathrm{~mm}$ have been used for the experimental research. Specimens for the cupping test have been taken from the plates of individual grades of sheets. The ten specimens from each grade have been evaluated. Individual grades of sheets have been labelled - A, B, C, D.

Chemical composition of the examined materials is presented in the Table 1 and labelling of these materials is shown in the Table 2.

\section{EXPERIMENTAL PROCEDURE}

Drawing tool with the mechanical blank holder with the adjustable holding force was designed by the Department of Mechanical Engineering Technology and Materials. The tool has been constructed in such a way that it can be used on the blasting machine ZD 40.

During the drawing of the cups, the punch with the diameter of $33.00 \mathrm{~mm}$ and the corresponding die with the appropriate tolerance $33.49+0.01 \mathrm{~mm}$ were chosen. Diameter of the blank was $55.00 \mathrm{~mm}$, which corresponded with the drawing degree 1.66. Semi-diameter of the drawing edge radius of the punch $\mathrm{r}_{\mathrm{p}}$ was $4.75 \mathrm{~mm}$ and the semi-diameter of the drawing edge radius of the die $r_{t}$ was $2.20 \mathrm{~mm}$.
Testing tool for the evaluation of anisotropy by the cupping test is shown in Fig. 1 .

Anisotropy of examined materials was expressed:

- by the earring coefficient " $\mathrm{Z}$ "

$$
Z=\frac{H_{\max }-H_{\min }}{H_{\min }} \cdot 100
$$

- by the earring degree " $\Delta \mathrm{H}$ “

$$
\Delta H=\frac{H_{0}-2 H_{45}+H_{90}}{2}[\mathrm{~mm}]
$$

where: $D H$ - earring degree [mm],

$H_{0^{\prime}} H_{45^{\prime}}, H_{90}$ - cup height in the direction $0^{\circ}, 45^{\circ}$ and $90^{\circ}$, in accordance with the rolling direction [mm],

$Z$ - earring coefficient [\%],

$H_{\text {max }} H_{\text {min }}-$ maximum and minimum cup height $[\mathrm{mm}]$.

Calculated values of the earring coefficient " $\mathrm{Z}$ " and the earring degree " $\Delta \mathrm{H}^{\prime}$ " of the examined packaging sheets are presented in the Table 3 . Average values have been calculated from 10 specimens (10 specimens from each grade of sheet).

After the cupping test, it is observable that individual cups possess an uneven height along their circumpherences. Difference between the maximum and the minimum height is called ear (Fig.2).

Table 1. Chemical composition of DR packaging sheets

\begin{tabular}{|c|c|c|c|c|}
\hline Sheet number & Coil 1 & Coil 2 & Coil 3 & Coil 4 \\
\hline $\mathrm{C}[\%]$ & 0.060 & 0.034 & 0.036 & 0.041 \\
\hline $\mathrm{Mn}[\%]$ & 0.267 & 0.160 & 0.169 & 0.160 \\
\hline $\mathrm{Si}[\%]$ & 0.010 & 0.000 & 0.006 & 0.000 \\
\hline $\mathrm{P}[\%]$ & 0.008 & 0.008 & 0.010 & 0.011 \\
\hline $\mathrm{S}[\%]$ & 0.010 & 0.012 & 0.009 & 0.036 \\
\hline $\mathrm{Al}[\%]$ & 0.045 & 0.050 & 0.044 & 0.004 \\
\hline $\mathrm{N}[\%]$ & 0.005 & 0.004 & 0.004 & 0.038 \\
\hline $\mathrm{Cu}[\%]$ & 0.056 & 0.051 & 0.033 & 0.018 \\
\hline $\mathrm{Ni}[\%]$ & 0.021 & 0.020 & 0.015 & 0.020 \\
\hline $\mathrm{Cr}[\%]$ & 0.020 & 0.017 & 0.020 & 0.005 \\
\hline $\mathrm{As}[\%]$ & 0.005 & 0.005 & 0.007 & 0.002 \\
\hline $\mathrm{Ti}[\%]$ & 0.001 & 0.002 & 0.001 & 0.003 \\
\hline $\mathrm{V}[\%]$ & 0.001 & 0.003 & 0.002 & 0.003 \\
\hline $\mathrm{Nb}[\%]$ & 0.002 & 0.003 & 0.002 & 0.000 \\
\hline $\mathrm{Mo}[\%]$ & 0.004 & 0.003 & 0.003 & \\
\hline $\mathrm{Zr}[\%]$ & 0.001 & 0.000 & 0.001 & \\
\hline
\end{tabular}


Table 2. Labelling of experimental material

\begin{tabular}{|c|c|c|c|}
\hline Coil number & Label & $\begin{array}{c}\text { Sheet } \\
\text { thickness } \\
{[\mathrm{mm}]}\end{array}$ & $\begin{array}{c}\text { Simplified } \\
\text { label }\end{array}$ \\
\hline Coil 1 & DR CA & 0.17 & A \\
\hline Coil 2 & DR CA & 0.17 & B \\
\hline Coil 3 & DR CA & 0.17 & C \\
\hline Coil4 & DR CA & 0.17 & D \\
\hline
\end{tabular}

\section{RESULTS AND DISCUSSION}

To allocate the critical area of the cups and the direction of the changes in the cup thickness in the individual directions of the drawing, it was necessary to estimate the change in the cup thickness. Thickness of individual cups was measured at the bottom of the cup, before the semi-diameter of the cup radius, on the semi-diameter of the cup radius, behind the semi-diameter of the cup radius, and along the wall of the cup. Intended cutting plane, where thickness was measured, goes through the centre of the cup in a parallel way to the directions $0^{\circ}, 45^{\circ}, 90^{\circ}$ in accordance to the rolling direction. To make the measured areas accessible, the cup was sectioned $5 \mathrm{~mm}$ from the intended cutting plane.

Measuring the change in the thickness was done in three directions, perpendicularly to the rolling direction, in the rolling direction, and at $45^{\circ}$ according to the rolling direction. Directions and positions of the sections are shown in Fig. 3.

Each section was divided into 7 parts measurement points. Division of the sections is shown in Fig. 4. The specimen was prepared in such a way that would enable to realize measuring of all marked spots with satisfactory accuracy.
Before the deformation of the specimen, thickness $\mathrm{a}_{0}$ was measured at each measurement point and in each direction, using the micrometer (micrometer screw gauge). Consequently, cupping test was carried out, during which cylindrical cups with flat bottoms were pulled out with a certain tensile strength F. After the cupping test, thickness of the cup specimens was measured again (at the same measurement points and in the same directions). Thickness of the specimens and cups was measured with the accuracy the $0.001 \mathrm{~mm}$.

Relative thinning was calculated according to this relation:

$$
a_{p}=\left(\frac{a_{0}-a_{i}}{a_{0}}\right) \cdot 100
$$

Fig. 5 presents graphical dependency of the relative thinning in the measured places of the cups from the examined sheet " $A$ ".

Fig. 6 presents graphical dependency of relative thinning in the measured places on the cups from the examined sheet "“B“.

Fig. 7 shows graphical dependency of the relative thinning in the measured places of the cups from the sheet " $\mathrm{C}$ ".

Fig. 8 presents graphical dependency of the relative thinning in the measured areas of the cups from the examined sheet " $D$ ".

From the relative thinning of the cups' thickness in accordance with the cup length $1_{p}$ it is possible to assume:

- at the bottom area of the cup (section 1 and 2), it is visible that there is a small reduction of thickness in all directions (up to 1\%), in the case of the sheet "B", thickness reduced by $2.3 \%$.

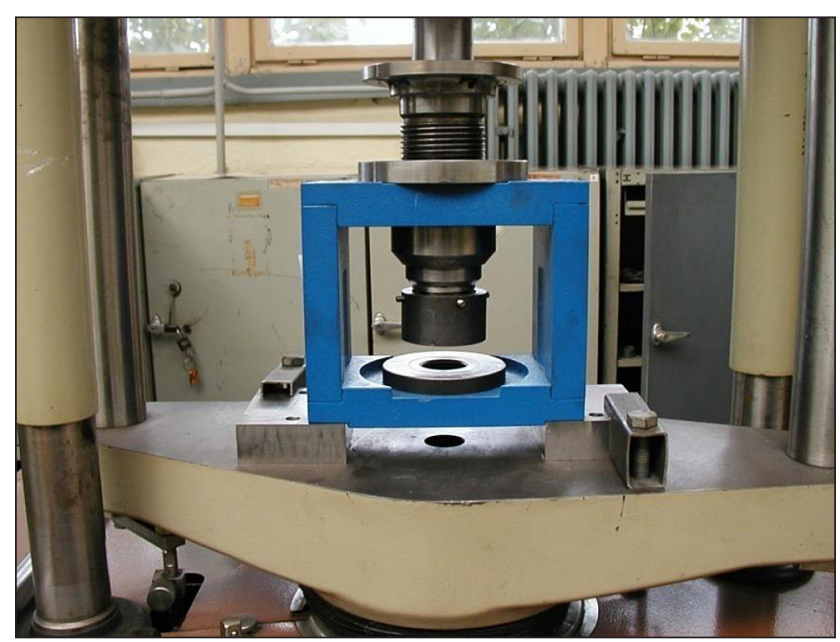

Fig. 1. Cupping test tool 
Table 3. Calculated earring values of DR packaging sheets

\begin{tabular}{|c|c|c|}
\hline Sheet grade & $\begin{array}{c}\text { Average value } \\
\text { Z [\%] }\end{array}$ & $\begin{array}{c}\text { Average value } \Delta \mathrm{H} \\
{[\mathrm{mm}]}\end{array}$ \\
\hline A & 3.65 & -0.49 \\
\hline B & 3.36 & -0.40 \\
\hline C & 3.25 & -0.36 \\
\hline D & 2.55 & -0.33 \\
\hline
\end{tabular}

- Right before the semi-diameter of radius (section 3), no material thinning occurs, on the contrary, material has grown thicker.

- In the area where the bottom and the wall join - area of the cup radius (section 4) - the most considerable thinning of the cup occurs almost in all directions - in the case of the sheet " $\mathrm{B}$ " it is most considerable in the direction $90^{\circ}(1.7 \%)$, and in the case of the sheet " $\mathrm{C}$ " in the direction $0^{\circ}(1.2 \%)$.
- From the area of the semi-diameter of the cup radius (section 4) to the edge of the radius semi-diameter (section 5), thickness gradually increases all the way to the cylindrical wall of the cup (section 6).

- In the area of the cup's cylindrical wall, cup thickness increases all the way to the edge of the cup. Thickening of the wall is the most considerable at the lower ear and less considerable at the upper ear. Thickness of the cups made from the sheet " $\mathrm{A}$ ", sheet " $\mathrm{C}$ ", and the sheet " $\mathrm{D}$ " reaches $0.217-0.219-0.220 \mathrm{~mm}$ $(27 \%)$ in the direction $0^{\circ}$ and $90^{\circ}$.

Change in the thickness of the materials " $\mathrm{A}$ ", " $\mathrm{B}$ ", " $\mathrm{C}$ ", and " $\mathrm{D}$ " is typical for the cylindrical cups with the flat bottom, which are drawn during the cupping test. Largest thinning was measured on the radius semi-diameter (section 4), which is the critical area of the cup.

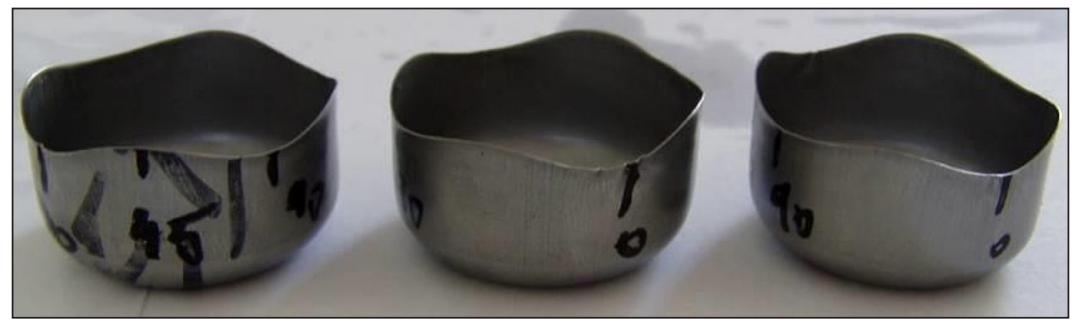

Fig. 2. Specimens with a considerable earring (lowest point of the cup in the direction $0^{\circ}$ and $90^{\circ}$ )
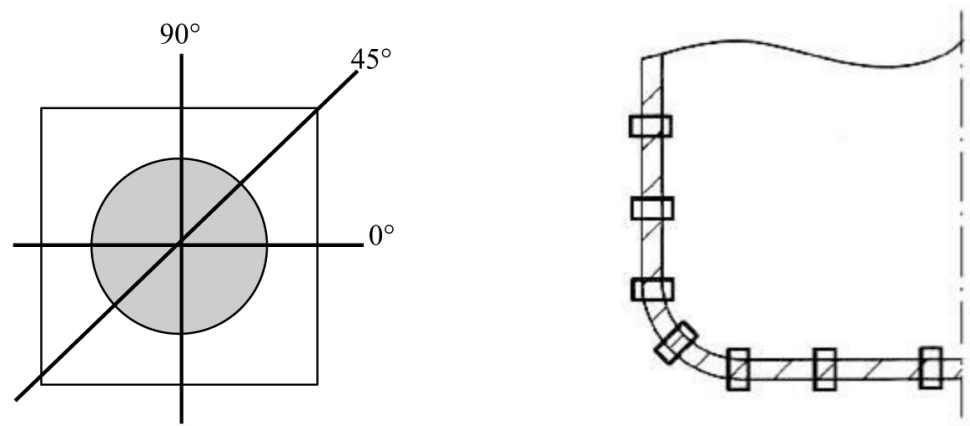

Fig. 3. Illustration of the directions on the cup and the position of measured areas of the cup

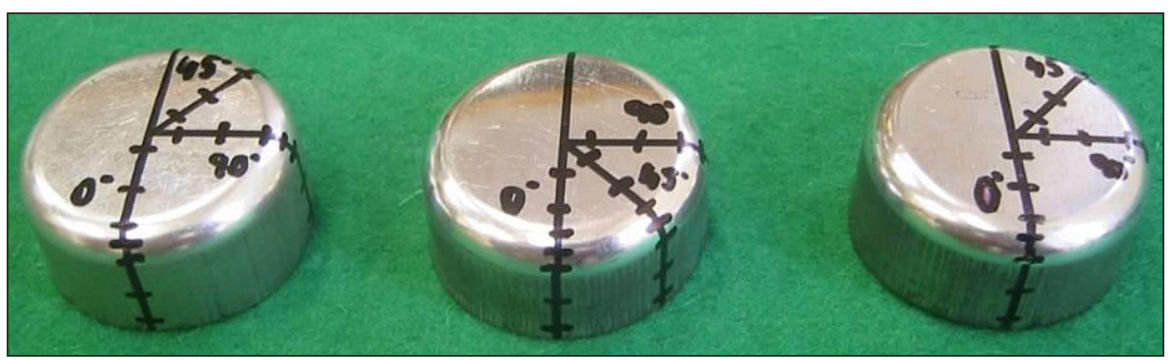

Fig. 4. Specimens of the double reduced packaging sheet of the examined grades (before measurement) 


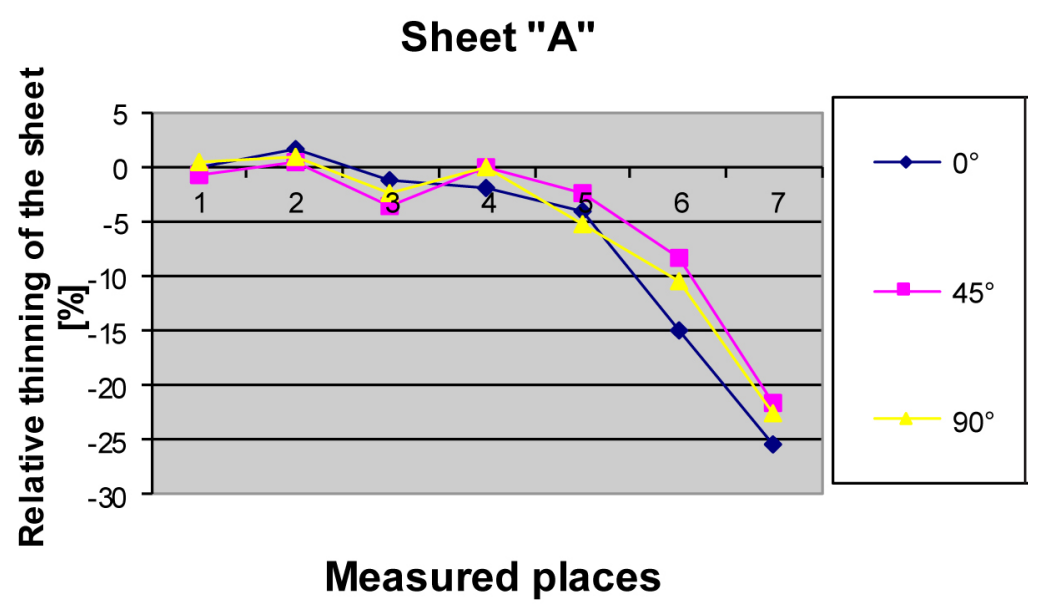

Fig. 5. Relative thinning of the sheet " $A$ "

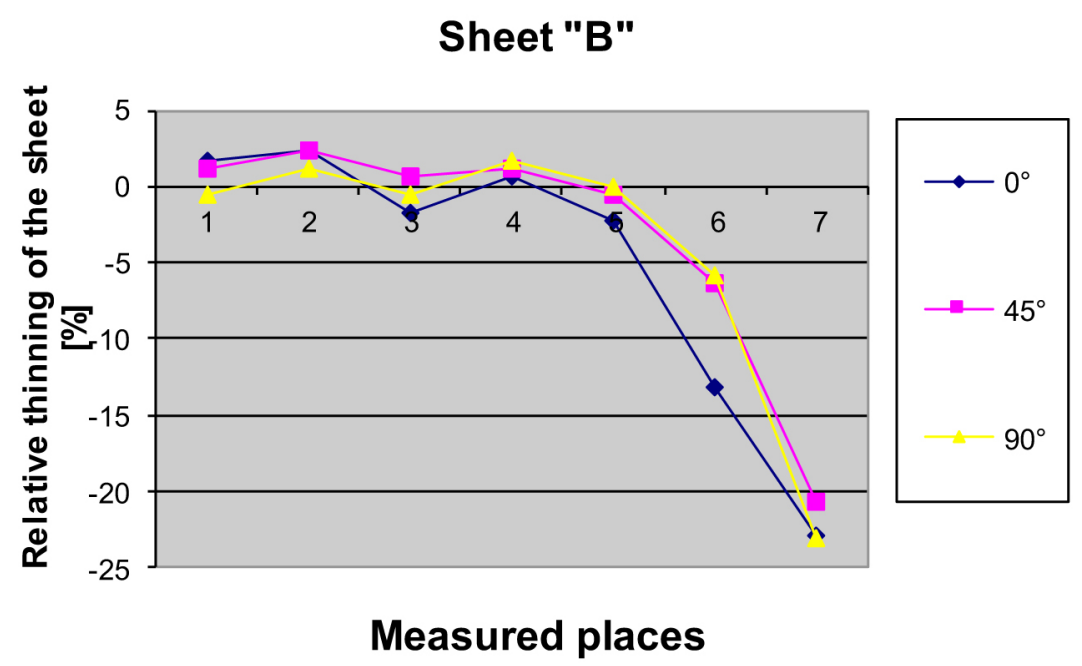

Fig. 6. Relative thinning of the sheet " $\mathrm{B}$ " in the measured places of the cup

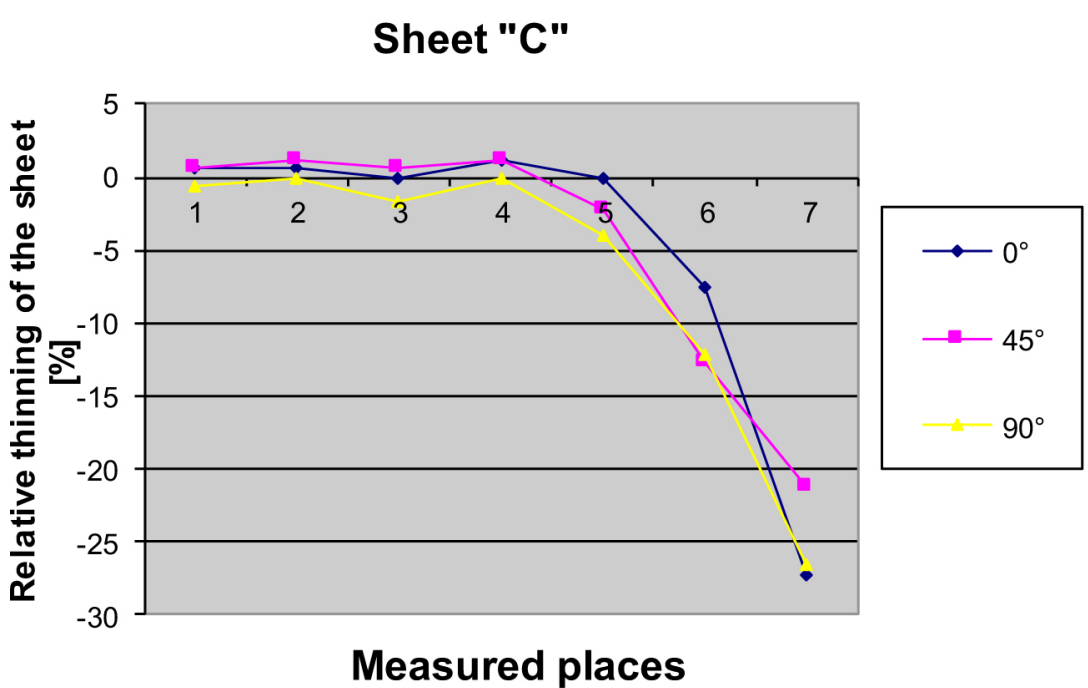

Fig. 7. Relative thinning of the sheet " $\mathrm{C}$ " in the measured places of the cup 


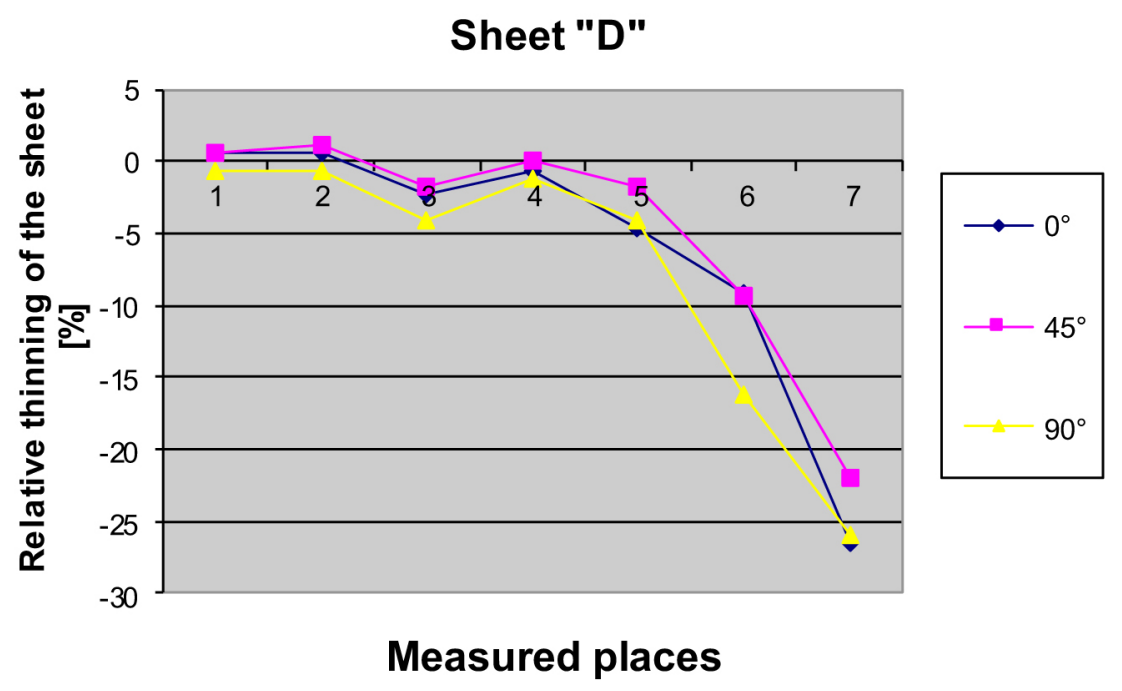

Fig. 8. Relative thinning of the sheet " $\mathrm{D}$ " in the measured places of the cup

Examined material showed the maximum thinning in the direction $45^{\circ}$, which means that DR packaging sheets possessed the highest earing in the direction $45^{\circ}$, and that is caused thinning of the cup, which resulted in the maximum relative thinning of the sheet. Materials with the lower endurance to the change in the thickness of the cup (with the lower value of the normal anisotropy coefficient) showed more considerable growth in the thickness.

Recent research [5, 8-11] in the field of the change in thickness of the sheets during the deep drawing has shown that the thinning of the cups made from low-carbon sheets shows directional dependency in the correlation with the directional progress of the normal anisotropy coefficient, which is applicable for the axially symmetrical shapes of the cups drawn during the classic drawing. Therefore, examined materials - considering the anisotropy process of deep drawing - are expected to show the maximum thinning in the direction $45^{\circ}$.

\section{CONCLUSIONS}

From the results of the measurement of the relative thinning of the sheets, it can be assumed that all the examined materials are appropriate for the deep drawing of the cups.

During the practical deep-drawing tests, material " $A$ " showed considerable ears in the direction $45^{\circ}$ and material " $D$ " showed very little earring with ear creation tendency in the direction $45^{\circ}$. From the change of the proportional thickness in accordance with the unreeled length of the cup, obtained by the measurement of the thickness changes on the cups in the directions $0^{\circ}, 45^{\circ}$, and $90^{\circ}$, it can be assumed that the maximum thinning was measured on all of the examined materials in the directions $45^{\circ}$. Maximum thinning on the material " $\mathrm{B}$ " was proved to be in the direction $90^{\circ}$, in the area of the radius semi-diameter and on the edge of the radius semi-diameter (where it joins the wall of the cup), where material thickness decreased from $0.173 \mathrm{~mm}$ to $0.170 \mathrm{~mm}$, which represents $1.7 \%$ relative thinning of the material thickness.

Thickening of the cup edges, in the case of all materials, was largest in the direction $0^{\circ}$ and $90^{\circ}$. Thickening in the direction $45^{\circ}$ was smaller. Maximum thickness of the cup edge from material "C" in the direction $0^{\circ}$ and $90^{\circ}$ was $0.219 \mathrm{~mm}$, where original average thickness of the sheet was $0.172 \mathrm{~mm}$. Thickening of the cup edge represents $27 \%$ thickening.

Overall progress of the change in the thickness of the sheet " $\mathrm{D}$ " is more fluent with the less significant maximum thinning and thickening of the cup edge. It is possible to say that this material has been drawn fluently and evenly along its entire length during the process of deep drawing. Material "D" possesses quality plastic properties in comparison to the other examined materials.

From all the measured results of the change in the material thickness during the cupping test, it can be clearly concluded that all the examined materials experienced only minimal thinning of the cup. This change in the thickness (less than $2 \%$ ) does not cause any considerable change in the thickness of the tin layer, thus it does not influence the corrosion resistance. 


\section{Acknowledgements}

The authors are grateful to APVV for support of experimental work under grant APVV14-0834 and the project VEGA No. 1/0441/17.

\section{REFERENCES}

1. Kalpakjian, S.: Manufacturing Engineering and Technology, Addison - Wesley Publishing Company, USA, 1990.

2. Zubko, P., Vojtko, M., Pešek, L., Német, M., Bekeč, P., Changes in mechanical properties and microstructure after quasi-static and dynamic tensile loading, Materials Science Forum, No. 782 (2014) 215-218.

3. Michel', J., Buršák, M., Lacková, P., Influence of the strain rate and heat treatment on the mechanical properties of steel sheets, Key Engineering Materials, No. 635 (2015) 100-105.

4. Peterkova, E., Srefl, M., Use of 3D measuring system aramis for analysis of tube flaring process, MM Science Journal, No. 2016 (2016) 1392-1397.

5. Stachowicz, F., Effects of microstructure on the mechanical properties and limit strains in uniaxial and biaxial stretching. Journal of M.W.T., No. 19 (1989) 305-317.

6. Sing, W.M., Rao, K.P., Role of strain hardening laws in prediction of forming limit curve, Journal of Material Processing Technology, No. 63 (1997) 105-110.

7. Sing, W.M., Rao, K.P., On the prediction of the effect of process parameters upon forming limit strain in sheet metals, Journal of Mechanical Sciences, No. 42 (2000) 451-470.

8. Spišák, E., Greškovič, F., Slota, J., Evaluation of plastic properties of tinned steel sheets, Rudy Metale, No. 42 (11) (1997) 510-512.

9. Spišák, E., Džupon, M., Majerníková, J., Spišáková Dul'ová, E., Failure of coatings of tinplates, Acta Metalla Slovaca, No. 21(3) (2015), 213-219.

10. Hill, R., On discontinuous plastic states with special reference to localized necking in thin sheets, J Mech Phys, No. 1 (1952) 19-30.

11. Zhang, J., Jiang, Y., A study of inhomogeneous plastic deformation of 1045 steel, J Eng Mater Technol, No. 126 (2004), 164-172.

12. Wang, X., Zhu, Z., Cai, F., Li, H., Effects of continuous annealing process on microstructure and properties of electrolytic tinplate, Heat Treatment of Metals, No. 38 (6) (2013) 49-54.

13. Banabic, D. Advanced anistropic yield criteria. In Sheet Metal Forming Processes, 1st edition; Springer Heidelberg

14. Dordrecht, Berlin, Germany, 2010, pp. 76-87, ISBN 978-3-540-88112-4

15. Jung, J, B; Jun, S; Lee, H,S; Kim, B,M; Lee, M,G; Kim, J,H. Anisotropic Hardening Behaviour and Springback of Advanced High-Strength Steels, Metals 2017, 7, pp. 480.

16. Banu M, Takamura M, Hama T, Naidim O, Teodosiu C, Makinouchi A. Simulation of springback and wrinkling in stamping of a dual phase steel rail-shaped part, J Mater Process Technol 2006, pp. 173-178. 10.1016/j.jmatprotec.2005.11.023. 